\title{
Geografia e trabalho; teoria e método
}

\section{Geography and labor; theory and method}

\section{Geografía y trabajo; teoría y método en Geografía}

\author{
Sócrates Menezes ${ }^{1}$ https://orcid.org/0000-0002-8330-9999
}

\footnotetext{
${ }^{1}$ Doutor em geografía- USP - São Paulo-SP, Professor adjunto do Departamento de Geografia -DG, docente permanente do PPGEO-UESB-Bahia-Brasil, socratesmenezes@yahoo.com.br
}

\section{Resumo}

O presente artigo tem como objetivo analisar a relação entre a ciência geográfica e a categoria trabalho, objetivando as dimensões teórica e metodológica que envolve o debate. A respeito da teoria, a discussão seguiu no sentido de entender os significados do valor-trabalho e da relação sociedade natureza, bem como as possibilidades de sua inserção na análise geográfica. A respeito do método, a discussão se orientou no debate sobre a dialética e sua constituição a partir de Hegel e Marx, demonstrando como que ela é o resultado interpretativo das contradições reais estabelecidas no interior da relação capital-trabalho, própria da sociedade moderna. Por fim, o texto conclui com um chamado à repensar a importância da centralidade do trabalho para a Geografia.

Palabras cHave: Geografia e trabalho. Teoria e método em Geografia. Geografia e dialética.

\begin{abstract}
The present article aims to analyse the relation among geographical science and the category work, aiming theoretical and methodological dimensions which involves the debate. In regards of the theory, the discussion followed on to understand the meanings of work-value and the relation society nature, as well as the possibilities of its insertion in geographic analysis. In regards of the method, the discussion oriented itself in the debate on dialectics and its constitution from Hegel and Marx's perspective, demonstrating how it is the interpretive result of the real contradictions established within the capital-labor relation, typical of modern society. Lastly, the text concludes with an alarm to rethink the importance of work centrality for the Geography.
\end{abstract}

Keywords: Geography and labor. Theory and method in Geography. Geography and dialectic 


\section{Resumen}

El presente artículo tiene como objetivo analizar la relación entre la ciencia geográfica y la categoria trabajo, objetivando las dimensiones teórica y metodológica que involucra el debate. Sobre la teoría, la discusíon siguío para comprender los significados del valor-trabajo y de la relación sociedad naturaleza, así como las posibilidades de su inserción en el análisis geográfico. En cuanto al método, la discusión se orientó en el debate sobre la dialéctica y su constitución desde Hegel y Marx, demostrando cómo ella es el resultado interpretativo de las contradicciones reales establecidas dentro de la relación capital-trabajo, propria de la sociedad moderna. Por último, el texto concluye con una alarma para repensar la importancia de la centralidad del trabajo para la Geografía.

Palavras-chave: Geografía y trabajo. Teoría y método en Geografía. Geografía y dialéctica.

\section{Introdução}

A categoria trabalho corresponde ao pensamento econômico e social. Desde o final do século XIX, as ciências sociais têm se apropriado dela para melhor compreender a realidade socialmente determinada segundo o conjunto de leis que regem o capitalismo. Antes disso, ainda no século XVIII, o trabalho foi a verdadeira chave para o entendimento das modernas relações de produção que envolvem o trabalho assalariado e o capital industrial, em franca expansão pela Europa e pelo mundo ${ }^{2}$.

$\mathrm{Na}$ Geografia, o trabalho, como categoria de análise, é introduzida por Camille Valaux, de forma central, no início do século XX. Para o geógrafo francês, diante da tentativa de solucionar a polêmica entre deterministas e possibilistas, a Geografia seria o estudo do “quarto estado da matéria", aquela produzida pelo trabalho humano ${ }^{3}$. O geógrafo italiano, Renée Rochefort, publica em 1961 o que pode ser considerado o primeiro estudo em Geografia sobre as relações e as condições de trabalho em uma determinada região. Le Travail en Sicile: Étude de Géographie Sociale ("O Trabalho na Sicília: Estudo de Geografia

\footnotetext{
${ }^{2}$ A própria "economia moderna", cientificamente consolidada, só assim se torna porque descobre no trabalho (abstrato) o fundamento da riqueza produzida pela sociedade, e não as trocas comerciais. É mérito da economia burguesa tal descoberta, especificamente dos fisiocratas, que entendiam apenas o trabalho na agricultura aquele gerador o valor da riqueza: "Eles [os fisiocratas] são, portanto, os pais da economia moderna" (MARX, 2011; p. 259).

3 "Aquele criado pelo trabalho humano, e assim [cabendo à Geografia] discutir 'a transformação aparente das coisas da superfície realizada pelo homem"” (MORAES, 2002; p.74). Ideias como essas aparecem, sobretudo, em obras seminais de Vallaux, como "Les Sciences Géographiques", de 1929.
} 
Social”, tradução nossa), se destaca por apresentar uma Geografia que se pretendia social, a partir da análise descritiva e quantitativa sobre as condições de vida e trabalho dos sicilianos.

No entanto, foi em Pierre George que a categoria trabalho ganhou mais destaque. Em todo conjunto de textos que versaram sobre a Geografia econômica, desde o final da década de 1950 até a publicação de Populações Ativas em 1978, é evidente a orientação do geógrafo francês para uma ciência que pretendia ser crítica e conectada com a realidade social do mundo em constante ciclos de crise. A importância de Pierre George é basilar porque, além de propor efetivamente uma Geografia do Trabalho ${ }^{4}$, foi um intelectual que exerceu muita influência na ciência geográfica, especialmente no Brasil. Mas o projeto de uma "geografia do trabalho" em Pierre George não chegou a se efetivar por uma série de limitações teóricas e epistemológicas que impossibilitaram o seu desenvolvimento ${ }^{5}$. Atualmente, no Brasil, o debate geográfico que tem como referência o trabalho tem ganhado força, principalmente, a partir de autores como Ruy Moreira ${ }^{6}$ e Antônio Thomaz Junior ${ }^{7}$.

$\mathrm{Na}$ esteira histórica de tantos geógrafos e algumas obras que relacionam a Geografia e o trabalho é importante observar dois vieses: o primeiro se refere àquelas perspectivas que buscaram na categoria trabalho uma referência sociológica, ou de criticidade à sociedade capitalista, colocando-o como objeto de estudo da própria análise geográfica. Elas buscaram se efetivar como uma perspectiva disciplinar, instituída no cenário científico e acadêmico, contribuindo com a análise territorial da contradição capital versus trabalho. O segundo viés se refere àquelas perspectivas que tomam o trabalho como temática de pesquisas. Interessam por assuntos relacionados às condições de sobrevivência da classe trabalhadora na cidade e no campo e às formas concretas das relações e exploração do trabalho. Estas são menos formais, porém mais restrita à empiricidade do trabalho no espaço.

Seja como objeto de pesquisa para a Geografia, ou como temática, é importante destacar que a categoria trabalho carrega em torno de si um complexo teórico-metodológico do qual a Geografia ainda não conseguiu se apropriar. Abaixo estão selecionados alguns

\footnotetext{
4 "Desse modo vemos se desenhar progressivamente os objetos de uma geografia do trabalho: / - a distinção de sistemas técnicos, econômicos e sociais que comportam formas particulares de articulação das diferentes atividades, de divisão da "força de trabalho" conforme formas e lugares de trabalho. / - a avaliação das taxas de utilização da força de trabalho e de suas estruturas e técnicas; / - o local do trabalho no tempo e espaço vivido, a gênese de um direito do trabalho e dos quadros institucionais no plano nacional e internacional." (GEORGE, 1979, p. 13)

5 “Cedo esta dialética [na Geografia Econômica de George] de 'riqueza versus pobreza' mostrar-se-á uma dialética pobre. Apenas se prepara o salto para fora dos quadros da 'geografia oficial”" (MOREIRA, 1994, p. 52).

${ }^{6}$ Ruy Moreira entende a "geografia do trabalho", assim, "com letra minúscula, não como uma nova corrente da Geografia" (MOREIRA, 2001, p. 42), aquela voltada para o conjunto de temáticas que envolve as relações de produção e as condições do trabalhador no processo de produção do espaço.

${ }^{7}$ Para Thomaz Junior, a "Geografia do Trabalho", assim, com iniciais maiúsculas, "como as demais disciplinas ou ramos do conhecimento científico" (TOMBAZ JUNIOR, 2002, P. 17), deve tomar o trabalho como objeto de estudo permanente da reflexão de da práxis da pesquisa.
} 
MENEZES, O. S.

pontos que necessitam ser reposicionados dentro da teoria geográfica no sentido de expandir o potencial explicativo que o trabalho pode trazer à esta ciência.

\section{A Teoria}

\section{[Valor-Trabalho]}

Quando se fala em categoria, tanto da filosofia como do pensamento geográfico, ou de qualquer outro campo científico, deve-se ter a exata noção de que elas se referem há uma forma de entendimento da realidade. Ou seja, a sua origem, ou concepção, não poderia advir senão da própria realidade concreta da qual ele emergiu, enquanto representação ideal dessa realidade, e deve voltar a ela servindo como instrumento explicativo. Qualquer realidade imediata nos é apresentada de forma caótica. As categorias servem para organizar no pensamento a realidade que precisa ser explicada. Supor que as categorias contenham em si mesmas, por meio do entendimento de seus conceitos, explicações suficientes da realidade é não se atentar para a possibilidade dos equívocos e dos erros que tanto marcaram os idealistas e os positivistas na história das ciência.

Neste sentido, a categoria trabalho deve ser apresentada como um esforço de entendimento de uma realidade específica. Mas que realidade é essa? A realidade concreta que demarca o mundo moderno. Apesar de estar ela muito atrelada ao pensamento marxista, é importante destacar que o trabalho, como categoria econômica e social, tem suas origens burguesas. O próprio Karl Marx admite essa “descoberta” feita pela burguesia ao considerar ser mérito dos Fisiocratas ${ }^{8}$, os "pais da economia moderna", a descoberta da origem do valor da riqueza social como decorrente do trabalho desenvolvido na terra (agricultura). É também muito reconhecido por Marx a importância das análises de economistas liberais, como Adam Smith e David Ricardo, no desenvolvimento da reflexão sobre a moderna sociedade capitalista-industrial que se expandia no século XIX. No que se refere à filosofia, também é importante destacar as contribuições de Hegel, um dos mais importantes filósofos modernos, que via no trabalho a fonte de toda a riqueza, mas também de toda alienação, dessa mesma sociedade regida por profundas contradições. No entanto, nenhumas dessas referências burguesas (econômicas ou filosóficas) triunfaram, na sequência do debate moderno, como aquela elaborada por Marx. Primeiro porque todas as perspectivas teóricas burguesas do século XIX não conseguiram se reproduzir como corrente em constante atualização, com

\footnotetext{
${ }^{8}$ Corrente do pensamento que inaugura a economia como ciência moderna no século XVIII. Pautava-se pela explicação das relações econômica regida por um sistema orgânico de leis que aliava a atuação do homem (em processo produtivo) e a natureza (como base dessa produção).

9 "Eles [os fisiocratas] são, portanto, os pais da economia moderna" (MARX, 2011; p. 259).
} 
continuadores de suas bases teóricas. Segundo porque, a contundente crítica elabora por Marx e pelos marxistas aos seus opositores burgueses foi estrutural demais, a ponto de não restar qualquer análise que fuja das amarras de suas contradições denunciadas.

Mas o ponto fundamental que envolve o trabalho e que "une" burgueses e comunistas (pelo menos aqueles do século XIX), é que a atividade humana orientada é o fundamento, a substância, não apenas da riqueza, mas da essência das coisas necessárias para o desenvolvimento humano e sua coletividade social. Não há riqueza sem trabalho, porque não haveria valor em sua produção, nem para aquela que servisse para o autodesenvolvimento humano (valor de uso), nem para aquela que servisse para o desenvolvimento dos mercados (valor de troca).

A teoria do valor-trabalho assim surge como conceito explicativo da sociedade que "libera" o trabalho da servidão feudal e o "aprisiona" em sua específica relação de assalariamento. O trabalhador, deixando de ser servos ou escravos, estão livres para vender sua força de trabalho a qualquer patrão. Se colocam, então, em uma relação comum à todo mercado; à lei da oferta e da demanda. Quanto mais trabalhadores, mais oferta de trabalho; quanto mais oferta, menor o valor. O que aparece como uma relação justa, natural, do ponto de vista do mercado, é o objeto de toda a desigualdade, do ponto de vista sociológico, ainda mais quando se resgata o processo de formação histórico das classes trabalhadoras empobrecidas nação por nação.

A Geografia se encontra exatamente nessa conjunção, entre a capacidade produtiva das coisas existentes no mundo originada pelo trabalho humano; e no processo de apropriação desigual deste mesmo mundo produzido socialmente. Isso significa entender que os espaços construídos, as cidades, os campos produtivos e improdutivos, os centros, as periferias; os espaços em disputas, os territórios; os espaços organizados pelo Estado, pela tradição, pela cultura, as regiões; os espaços conservados pela indústria turística, ou como reserva de valor nas florestas tropicais, a "natureza"; os espaços produzidos pela industrialização, as cidades urbanas ou não; os objetos, as técnicas, etc. todas as formas de conceber o espaço na sociedade moderna não podem ser entendidos, senão como resultado do trabalho humano tomado em sua condição social.

Mas como produto do trabalho, ao mesmo tempo em que torna a condição do seu desenvolvimento, o espaço não pode ser definido como um ente "puro", definido em si mesmo. Esse mesmo espaço moderno, porque é próprio da sociedade moderna, deve admitir sua historicidade, sua gênese, portanto, sua transitoriedade. Como observa Lefebvre (2006), 
se o modo de produção é capitalista, o processo de produção do espaço é também capitalista. Ora, se o espaço se constitui como uma objetividade concreta, produto do trabalho humano, o mesmo processo de alienação capitalista do trabalho (mais-valia) deve incidir, também de forma objetiva, no processo de produção e apropriação do espaço. As análise espaciais que envolvem temáticas como segregação espacial, desigualdades urbanas, centro versus periferia, tem como gênese a própria alienação do trabalho, que nada mais significa do que o entendimento da contradição entre produção social e apropriação privada do meios de vida e reprodução social.

\section{[Sociedade-Natureza]}

Em passagem famosa, Marx afirma que:

Antes de tudo, o trabalho é um processo entre o homem e a Natureza [...]. Ele põe em movimento as forças naturais pertencentes a sua corporalidade, braços e pernas, cabeça e mão, a fim de apropriar-se da matéria natural numa forma útil para sua própria vida. Ao atuar, por meio desse movimento, sobre a Natureza externa a ele e ao modificá-la, ele modifica, ao mesmo tempo, sua própria natureza. Ele desenvolve as potências nela adormecidas e sujeita o jogo de suas forças a seu próprio domínio (MARX, 1983, p. 157).

Obviamente, tal passagem está contida em um complexo teórico próprio do pensamento marxiano, denominado por Gyögy Lukács como ontologia do ser social. Para este autor, ao aprofundar nos estudos sobre as contradições erigidas na sociedade moderna pela lógica do capital, Marx descobre que, na sociedade burguesa-industrial, o trabalho não é somente liberado de seus limites e aprisionamentos históricos, mas é ainda "des-coberto" como potência da própria humanização do homem. Desta forma, o trabalho não é somente a categoria que explica a origem do valor da riqueza produzida pelo homem, ou as contradições próprias das relações capitalistas de produção, mas se coloca também como uma categoria genérica, universal, que media a relação do homem com a natureza.

O trabalho, posto como ato produtivo a partir da mediação homem-natureza, não produz apenas coisas novas e necessárias à vida humana, objetos e mercadorias que nos servem ou servem às trocas e ao desenvolvimento dos mercados, mas produz também o próprio homem. O ato autoprodutivo do homem pelo trabalho está relacionado a sua capacidade de produzir, genericamente, o seu ambiente, o seu espaço. Na medida em que o homem trabalha, e ao se relacionar com a natureza e produzir seu espaço, produz a si mesmo, como sujeito histórico que é. Produz, dessa forma, uma natureza humanizada, seu espaço, não 
puramente natural, mas social, na medida em que todo ato de produção e de trabalho seja também um ato social. Dessa forma, produz um tipo de natureza, uma "segunda natureza", por nós geógrafos denominada espaço, um espaço historicizado e socializado. E, ao desenvolver essa potência da produção na mediação homem-natureza, é que o trabalho se coloca como condição de socialização da natureza no desenvolvimento da natureza social humana.

\section{O Método}

\section{[Dialética do trabalho]}

O trabalho envolve a dialética própria da sociedade moderna. Isso significa que esta categoria carrega em si, além da historicidade que demarca o mundo capitalista e suas relações de produção, o próprio método de entendimento de como essas sociedade se desenvolve. Esta sociedade, capitalista, moderna, tem uma condição bastante específica em relação às demais que a precederam: a contradição. Assim como o trabalho, essa potência humana em socializar a natureza e desenvolver a natureza social humana, a dialética é "descoberta" no mesmo processo histórico, onde a condição material da história se torna determinante.

Hegel foi o filósofo responsável em trazer a dialética para os tempos modernos. $\mathrm{Na}$ antiguidade clássica grega, a dialética era entendida como a arte do confronto de ideias, o debate, o diálogo entre opostos. A reposição constante dos questionamentos cada vez mais profundos perante as verdade estabelecidas, que tanto caracterizou a maiêutica socrática, é um sintoma ainda primitivo da força da dialética estabelecida como método para o desenvolvimento do conhecimento. Na escolástica medieval, a dialética foi rebaixada ao discurso, na mesma intensidade em que o ato de questionar se tornou reprimível. Hegel, como filósofo moderno, vai revolucionar o pensamento filosófico ao repor a dialética em seu mais alto nível de sofisticação e complexidade, exatamente porque precisava explicar a complexa sociedade que se formava ao seu tempo: uma sociedade revolucionária, movida por profundas contradições internas, especialmente àquelas referentes à relação capital-trabalho.

Mas quais seriam os pontos elementares dessa dialética redescoberta por Hegel?

Primeiro: a história como processualidade. Hegel foi contemporâneo da Revolução Francesa. Ao analisar o processo histórico em marcha, o filósofo alemão observou que, diferente do tempo (que se dá de forma linear e absoluta), a história tem uma forma relativa e socialmente determinada. Isso significa que os grandes eventos históricos não devem 
acontecer pelo simples fato de "o tempo passar" e a mudança se tornar algo "naturalmente necessário", mas porque a intensidade do conflito entre os interesses em conservar o mundo como ele é e os interesses em tornar o mundo como pode ser, chegam a limites insuportáveis. As revoluções, que promovem grandes saltos históricos, são frutos de grandes explosões de energias sociais acumuladas por algum tempo. Portanto, diferente do tempo, a história não se processa de forma linear, mas como uma tensão entre profundas contradições que, em um dado momento, deve se romper, mudando radicalmente a ordem estabelecida ${ }^{10}$. Para a burguesia revolucionária do seu tempo (início do século XIX), Hegel havia se tornado o seu principal filósofo, na medida em que sua teoria revolucionária estava alinhada às necessidades de consolidação da burguesia como classe dominante na economia e na política.

Segundo: a gênese e a transitoriedade: tudo aquilo que se coloca como objeto da reflexão filosófica ou científica, tem uma determinada e específica lógica interna. Os problemas humanos reais podem ser explicados a partir de sua formação histórica. Isso significa resgatar o passado para tentar entender os problemas reais imediatos do presente. Mas o "retorno ao passado" concede penas uma explicação parcial do objeto analisado. Todos os objetos em observação filosófica ou científica, além da formação, tem algo mais preponderante: uma gênese. A gênese se refere ao conjunto interno das categorias e relações que definem a propriedade específica do objeto analisado. Por exemplo, a sociedade capitalista é explicada pelo complexo contraditório entre trabalho assalariado, capital como processo de autovalorização do dinheiro pelo dinheiro, propriedade privada, Estado burguês, etc. Essas categorias, em franco estado de ebulição, explicam o funcionamento interno do capitalismo. Portanto, compõe sua gênese, sua lógica interna. Mesmo que seja possível observar em outros modos de produção a existência dessas mesmas categorias, aqui ou acolá, elas existiram de forma não determinante, portanto incapaz de promover em suas interações uma lógica interna própria, como é na sociedade capitalista. Admitida a gênese interna dos objetos em observação analítica, como a relação entre categorias contraditórias em profundo estado de conflito (capital $\mathrm{x}$ trabalho, p. ex.), significa que todos os objetos reais, filosóficos ou científicos, tem seus limites também internos. Ora, se tudo tem uma gênese, tudo tem seus limites de existência, tudo é transitório. O que determina os limites da existência e o momento da transitoriedade é a força explosiva ou não das tensões internas dessas categorias

\footnotetext{
10 “O senhor se relaciona mediatamente com o escravo por meio do ser independente, pois justamente ali o escravo está retido; essa é a sua cadeia, da qual não poderia abstrair-se na luta, e por isso se mostrou dependente, por ter sua independência na coisidade. O senhor é, porém, a potência sobre esse ser, pois mostrou na luta que tal ser só vale para ele como um negativo. O senhor é a potência que está por cima deste ser; ora, esse ser é a potência que está sobre o Outro; logo, o senhor tem esse Outro por baixo de si: é este o silogismo da dominação” (HEGEL, 2000, p. 130).
} 
em contradição e conflito. Se explodem, tem-se a revolução; se conservam, tem-se a continuidade do acúmulo dessas contradições em níveis ainda mais críticos. Portanto, para Hegel, a contradição é o motor da história; e a dialética a forma de entendimento organizado do seu espírito, o "espírito do tempo".

Com a dialética, Hegel conseguiu observar o funcionamento real da sociedade moderna; entendendo sua lógica interna a partir da contradição entre o aumento da capacidade produtiva socialmente dirigida pela industrialização capitalista e o processo de alienação do trabalho e empobrecimento da classe trabalhadora ${ }^{11}$. Hegel observou, corretamente, um novo estado de contradições se estabelecendo e se desenvolvendo no processo histórico: burguesia versus proletários. Mas, ideologicamente comprometido à classe dominante, a burguesia, Hegel preferiu oferecer soluções idealistas às contradições observadas, relegando ao Estado moderno e ao espírito racional a manutenção e o apaziguamento das contradições internas e explosivas. Cabia ao Estado, imperialista e racional, garantir (mesmo que por meio da força) a ordem do progresso burguês, na medida que este era entendido como o limite máximo do desenvolvimento histórico humano. Contraditoriamente, Hegel abre mão dos princípios filosóficos da processualidade e da transitoriedade histórica do objeto observado (a moderna sociedade capitalista) em prol da manutenção das coisas com que ele se identificava política e ideologicamente.

Caberia a Marx o reestabelecimento da dialética nos mais profundo níveis críticos. Assim é feito, primeiro, com um intensa crítica à Filosofia do Direito de Hegel, demonstrando as mistificações idealistas por ele promovidas, com a intencionalidade de deslegitimar o estado das coisas como estavam. Segundo: reconhecendo o potencial revolucionário da dialética redescoberta por Hegel, para que agora pudesse ser liberada das amarras ideológicas com que o filósofo alemão a havia aprisionada Marx opera a mais incisiva crítica à lógica social burguesa. Objetivamente, dando sequência à leitura das contradições reveladas pela análise dialética, Marx a inverte, traz para o chão concreto, para a materialidade da vida histórica e, consequentemente, oferece como solução a necessidade histórica da revolução, mas dessa vez sob o comando do proletariado, a verdadeira classe revolucionária do capitalismo. Assim depõe a favor da dialética:

\footnotetext{
11 "Hegel explica que a acrescente acumulação de riqueza, por um lado, e a produção da "ralé penuriosa", mergulhada nas profundezas da miséria e do desespero, por outro lado, criam o cenário para a instabilidade social e a guerra entre as classes, que não pode segundo sua análise, ser mitigada por qualquer transformação interna no funcionamento da sociedade civil. A superprodução e o subconsumo, provocados por desequilíbrios na distribuição de renda, também solapam a coerência interna do empreendimento industrial. A sociedade civil é forçada a buscar uma transformação externa por meio da expansão geográfica, pois sua “dialética interna” cria contradições, não admitindo soluções internas" (HARVEY, 2005, p. 101)
} 
A mistificação que a dialética sofre nas mãos de Hegel não impede, de modo algum, que ele tenha sido o primeiro a expor as suas formas gerais de movimento, de maneira ampla e consciente. É necessário invertê-la, para descobrir o cerne racional dentro do invólucro místico. [...] Em sua configuração racional, é um incômodo e um horror para a burguesia e para os seus porta-vozes doutrinários, porque, no entendimento positivo do existente, ela inclui ao mesmo tempo o entendimento da sua negação, da sua desaparição inevitável; porque apreende cada forma existente no fluxo do movimento, portanto também com seu lado transitório; porque não se deixa impressionar por nada e é, em sua essência, crítica e revolucionária" (MARX, 1983, p. 20-21).

O que Marx faz é dar prosseguimento aos objetivos filosóficos da dialética redescoberta por Hegel. Reconduz a sua processualidade revolucionária que lhe é própria. Reabre às possibilidades do devir histórico por meio de uma monumental investigação da sociedade moderna, no famoso O Capital. E assim, orienta sua investigação denunciado as especulações metafísicas, apresentando a realidade e demonstrando, cientificamente, os limites estruturais do capital por meio de suas contradições internas, portanto, expondo seu caráter transitório, além da necessidade de uma mudança estrutural, dada a potência destrutiva com que o capitalismo poderia levar a sociedade, como depois se verificou nas duas grandes guerras mundiais do século XX.

\section{Considerações finais}

Do ponto de vista da Geografia e das possibilidade de intepretação que ela possibilita, a centralidade da categoria trabalho é fundamental porque, primeiro, reestabelece a subjetividade humana no processo de produção do espaço. O espaço, reconhecido como produto do trabalho humano, não pode ser deslocado da objetividade da apropriação social de si mesmo. Segundo, porque reestabelece a contradição como motor da análise a ser investigada. Isso significa orientar a análise para a luta de classe, considerando os conflitos internos dos objetos analisados e, ao mesmo tempo, sua transitoriedade histórica.

Mas o ponto fundamental que a centralização do trabalho na epistemologia geográfica pode promover é o resgate da crítica social. Como lembram Costa e Moraes, retomando Marx no instigante Geografia Crítica: A Valorização do Espaço, "[...] só a perspectiva de transformar o mundo fornece a possibilidade de compreendê-lo" (MARX,1984, p. 35)

\section{Referências}


COSTA, W. M. da; MORAES, A. C. R, Geografia Crítica: A Valorização do Espaço, São Paulo, HUCITEC, 1984.

GEORGE, Pierre. Populações Ativas. São Paulo; DIFEL, 1979.

HARVEY, David. A Produção Capitalista do Espaço. São Paulo: Annablume, 2005

HEGEL, G. W. F. Fenomenologia do Espírito (parte I). Petrópolis: Vozes, 2000.

LEFEBVRE, Henri. A produção do espaço. Trad. Grupo "As (im)possibilidades do urbano na metrópole contemporânea", do Núcleo de Geografia Urbana da UFMG (do original: La production de l'espace. 4e éd. Paris: Éditions Anthropos, 2000). Primeira versão : início fev. 2006.

LUKÁCS, Gyögy. Para uma Ontologia do Ser Social, 2. São Paulo: Boitempo, 2013.

MARX, Karl. Grundrisse: manuscritos de 1857-1858: Boitempo, 2011.

MARX, Karl. O capital: crítica da economia política. São Paulo: Abril Cultural, 1983. v. 1, t. 1.

MORAES, Antônio Carlos Robert. Geografia, pequena história crítica. - São Paulo; HUCITEC, 2002.

MOREIRA, Ruy, "Trabalho e Movimentos Sociais no Brasil: um diálogo possível no âmbito da luta emancipatória?", In: II Jornada sobre o Trabalho. Caderno de Textos - Centro de Estudos de Geografia do Trabalho (CEGeT), Presidente Prudente, CEGeT, 2001.

ROCHEFORT, Renée. Le Travail en Sicile: Étude de Géographie Sociale; Presses Universitaires de France, Paris, 1961.

THOMAZ Junior, Antônio, "Por Uma Geografia do trabalho", Revista Pegada Eletrônica (Geografia), Vol. 3 (edição especial), Presidente Prudente, CEGET, 2002

VALLAUX, Camille. Les Sciences Géographiques. Paris; F. Alcan, 1929. 